\title{
Gênero, infância e relações de poder: interrogações epistemológicas"
}

\author{
Rita de Cássia Marchi**
}

\section{Resumo}

Este artigo relaciona as posições periféricas da mulher e da criança no campo científico $e$ as atuais dificuldades epistemológicas colocadas à emancipação da infância como categoria sociológica conceitualmente autônoma. Essas dificuldades são similares às resistências com que se depararam, tempos atrás, os "estudos feministas" para estabelecer o gênero como uma nova categoria de análise. A infância é uma construção social atravessada pelas relações assimétricas de poder $e$ ação entre as gerações na sociedade e, no campo científico, pela perspectiva adultocêntrica $e$ predominantemente masculina (androcêntrica) do conhecimento.

Palauras-chave: Estudos Sociais da Infância, Estudos de Gênero, Epistemologia.

\footnotetext{
* Recebido para publicação em 23 de julho de 2009, aceito em 13 de maio de 2010.

** Professora do Mestrado em Educação e do Curso de Ciências Sociais da Universidade Regional de Blumenau (FURB).rt.mc@bol.com.br
}

cadernos pagu (37), julho-dezembro de 2011: 387-406. 
Gênero, infância e relações de poder

Gender, Childhood and Relations of Power:

Epistemological Questions

\begin{abstract}
This article relates the peripheral positions of woman and child in the scientific field and the current epistemological difficulties towards the emancipation of childhood as a conceptually autonomous sociological category. These difficulties are similar to the resistance encountered some years ago by "feminist studies" to establish gender as a new category of analysis. Childhood is a phenomenon permeated, in the social field, by asymmetric relations of power and action between generations and, in the scientific field, by the adult-focused and predominantly masculine (androcentric) perspective of knowledge.
\end{abstract}

Key Words: Childhood Social Studies, Gender Studies, Epistemology. 
Este artigo tem por finalidade relacionar as posições periféricas da criança e da mulher no campo das ciências sociais $e$ discutir as dificuldades epistemológicas colocadas à emancipação da infância como categoria sociológica conceitualmente autônoma. ${ }^{1}$

A emancipação epistemológica da infância tem sido defendida pelos chamados novos estudos sociais da infância (entre eles, notadamente a Sociologia da Infância) que vêm se consolidando na arena científica internacional desde os anos 80 . Esses estudos propõem um novo paradigma para os estudos sobre a infância no contexto das atuais transformações que atingem instituições sociais centrais à vida das crianças. Transformações estas que podem ser vistas como resultados e, ao mesmo tempo, como produtoras de novas circunstâncias e condições de vida de crianças em todo o mundo.

Construída sobre a dupla afirmação da criança como ator $e$ da infância como construção social, a Sociologia da Infância reivindica, portanto, como condição necessária para a construção de um novo paradigma para os estudos sociais da infância, a sua declaração como objeto de estudo conceitualmente autônomo. ${ }^{2}$ Essa reivindicação decorre do fato da infância ter sido, até muito recentemente, ignorada em sua autonomia conceitual devido ao longo processo de marginalização que sofreu como objeto de estudo sociológico (Qvortrup, 1995; Sirota, 2001; Montandon, 2001). Trata-se, portanto, do movimento teórico de colocar a infância e as crianças em "equidade conceitual" relativamente a outros

\footnotetext{
1 Não me refiro aqui à "posição periférica" das mulheres no campo científico no sentido da sua sub-representação numérica nas ciências ou instituições científicas, como assinalam os estudos sobre gênero na história das ciências, mas ao fato de que a ação e o ponto de vista das mulheres - diferentemente das atividades $e$ pontos de vista dos homens - não constituíam ponto de interesse para as ciências sociais até pouco tempo atrás.

2 Sobre a gênese e a legitimação da sociologia da infância no campo científico e para um panorama de sua constituição interna - correntes, afiliações, problemáticas e controvérsias -, ver Sarmento (2000; 2006).
} 
Gênero, infância e relações de poder

grupos ou categorias sociais; isto é, reivindica-se nesse movimento a "cidadania epistemológica" da criança (Ferreira, 2002).

Pretende-se discutir neste artigo que a relação entre as posições periféricas da mulher e da criança no campo científico decorre do fato da infância ser vista como uma categoria "normal" e, por isso, facilmente transformável em "natural", tal como acontecia até pouco tempo atrás com as categorias "sexo" $e$ "raça" (Jenks, 2002). Para estabelecer essa relação sugiro que a posição inferiorizada da mulher na sociedade decorre em grande parte de sua proximidade física e simbólica com as crianças e, ainda, que no processo de "contaminação" do universo feminino pelo universo infantil, as crianças são o "ponto mais baixo" dessa escala valorativa. ${ }^{3}$ Para essa empreitada, serão consideradas as reflexões críticas realizadas no âmbito da Sociologia da Infância sobre as teorias tradicionais da socialização, entendendo que é dessa crítica que as relações entre poder, gênero e infância podem ser efetivamente estabelecidas.

\section{As teorias da socialização e a violência (poder) da teoria}

As críticas realizadas pela Sociologia da Infância às visões tradicionais da criança e sua socialização se debruçam sobre os quadros teóricos até agora dominantes no campo em que se trava essa batalha: nas áreas da psicologia do desenvolvimento, sociologia da educação e sociologia da família. Em relação à psicologia de desenvolvimento, as críticas se dirigem notadamente aos aspectos evolucionistas e deterministas do pensamento de Piaget, que liga fatos da imaturidade biológica da criança -como sua dependência - a aspectos sociais da infância (James; Prout, 1990). Nessa disciplina a "racionalidade adulta" é a marca a ser

\footnotetext{
${ }^{3} \mathrm{Na}$ lida com crianças e adolescentes, as mulheres também podem desempenhar, por delegação, a violência e a função patriarcal. Assim, na hierarquia social, as crianças estão "abaixo" das mulheres. Segundo Saffioti (2001), isso decorre do fato de que a sociedade não é apenas androcêntrica, mas também adultocêntrica.
} 
atingida através de estágios pré-determinados no desenvolvimento cognitivo da criança. Isto é, fundindo o domínio biológico ao social, a abordagem evolucionista transforma uma norma em fato, favorecendo a naturalização dos julgamentos de valor e tornandose elemento estruturador da experiência das crianças, que passam a ser moldadas por determinadas características descritivas (Jobim; Souza, 1996). A singularidade da criança nos estudos de Piaget é construída em torno da naturalidade e da universalidade da infância. Não há lugar, nesses estudos, para "as crianças" (em seus diversos níveis de heterogeneidade): "a" criança ("the child") como a manifestação física do desenvolvimento cognitivo da infância para a idade adulta representa, nessa teoria, todas as crianças (James; Prout,1990). ${ }^{4}$ Essa visão impede que a criança seja vista como um ser com direito a reconhecimento próprio, pois ela não é vista como um ser "no presente", mas um ser "em devir", um ser "no futuro", cuja existência passa a representar a "passagem" em direção à vida adulta. Nesse sentido, Qvortrup (1995) assinala a dubiedade do conceito de socialização em sua "tendência de antecipação": em termos de desenvolvimento individual, a socialização olha, por definição, sempre "em frente", afastando-se da infância e refletindo assim a ideia dessa etapa da vida como o desenvolvimento precoce de uma cultura de adultos.

Para James e Prout (1990), a construção científica da irracionalidade, naturalidade e universalidade da infância presente no discurso psicológico foi diretamente transferida, durante os anos 1950, para o campo do conhecimento sociológico da infância na forma das "teorias da socialização". 5 A compreensão estrutural funcionalista dominante no pensamento sociológico da época previa para o indivíduo um número finito de "papéis sociais". Assim, a socialização era entendida como o mecanismo pelo qual esses papéis podiam ser reproduzidos em sucessivas

\footnotetext{
4 A esse respeito, ver também James e James (2004).

5 Críticas desconstrucionistas das teorias pedagógicas surgiram também de dentro da própria pedagogia (cf. Charlot,1979, Narodowski ,2001).
} 
Gênero, infância e relações de poder

gerações. Socialização era, portanto, o processo através do qual um ser era "magicamente", na expressão de James e Prout (1990), transformado em outro: a chave pela qual a criança a-social se convertia num adulto socializado.

A Sociologia da Infância rompe, portanto, com as abordagens clássicas da socialização pelo fato destas tomarem a criança como um ser passivo e sempre "em trânsito" para a vida adulta (isto é, um ser "de passagem"). Assim, a mudança da visão da criança como objeto ou produto da ação adulta para a compreensão da criança também como um agente de sua própria socialização é a grande mudança que se estabelece. O esforço é o de revelar que, nos "papéis" de "filho" e "aluno", a criança que está ali não é um receptáculo passivo de socialização numa ordem social adulta. Em torno dessa nova concepção se ergueram os primeiros pilares da Sociologia da Infância (Sirota, 2001, 2006; Montandon, 2001; Ferreira, 2002). ${ }^{6}$

Alanen (1990), socióloga da infância que faz uso dos estudos de inspiração feminista sobre a família, ressalta que, se os estudos de gênero têm modificado a produção do conhecimento no que diz respeito à ação das mulheres, não têm, no entanto, feito o mesmo em relação às crianças, que permanecem sendo vistas como não-atores de sua própria socialização. É, portanto, a releitura crítica do conceito de socialização no quadro estruturalfuncionalista que leva não só a considerar a criança como um ator social, mas a despir de "naturalidade" e "desinteresse" a visão moderna de infância (Pinto, 1997) e de sua educação. Isso nos leva à compreensão do caráter essencialmente político das visões de

6 O paradigma da criança-ator não significa uma suposta autonomia absoluta da criança e nem a consideração de suas ações na ausência dos efeitos das propriedades estruturais e das relações sociais de poder e dominação. Antes, a questão diz respeito ao fato de se ligar os níveis micro e macro de investigação, tendo por objetivo compreender, sociologicamente, o lugar e a ação social das crianças (Sirota, 2005). Isto é, a produção no campo dos novos estudos sociais da infância analisa como a criança se constitui na relação com os adultos no interior mesmo de relação sociais concretas. 
infância/criança nas sociedades, porque relacionadas às questões do poder e da constituição e manutenção da ordem social.

Neste sentido, Jenks (2002) analisa as razões e bases políticas geradoras da existência e da imagem arquetípicas da criança na sociedade, assinalando que a criança - numa condição não socializada ${ }^{7}$ - é um ser profano que ameaça colapsar os mundos sociais. No campo teórico, de acordo com o autor, a mitigação dessa ameaça foi tarefa que a teoria da socialização se encarregou de realizar com a remoção da prática social da criança $e$ o seu tratamento através do arquétipo de proto-adulto. Ao criticar as "teorias reparadoras da socialização" (cujo paradigma é a teoria parsoniana dos sistemas), Jenks afirma que essas teorias "enlaçam" ou incorporam a infância dentro de seus parâmetros, entendendo-a como categoria residual e como um dado dos "sistemas sociais de sucesso". Nesse sentido, pode-se evidenciar o quanto os processos educacionais deveriam ser uma área de fundamental interesse sociológico, embora sua importância nem sempre seja reconhecida.

Durkheim, fundador da sociologia da educação, e Parsons, que (re)elaborou as teorias da socialização, certamente perceberam o caráter estratégico da educação na construção e manutenção da coesão e da ordem social. Isto é, a vertente estrutural-funcionalista sempre esteve abertamente preocupada com a compreensão teórica dos processos de ordenamento $e$ coesão social e com a função social das instituições centrais de uma sociedade, notadamente a instituição social da educação. Mas Jenks (2002) aponta para o outro lado da moeda: o autor evidencia como a análise crítica da visão funcionalista da educação pode revelar a "violência teórica" cometida contra a criança ao tentar converter seus "mundos de conteúdo" em "mundos de forma" através do conceito de socialização. Essa análise crítica revela, portanto, como a meta parsoniana fez da

7 Criança "de rua", fora da escola, "delinquente", etc. 
Gênero, infância e relações de poder

sociologia uma ciência moral cujo objetivo esteve centrado na produção de uma cidadania dócil (O’Neill, 1994 apud Jenks, 2002).

Para Jenks (2002:203), a criança, no âmbito da teoria da aprendizagem, é sistematicamente desumanizada e excluída tal qual na teoria social: "criam-se e manipulam-se determinadas versões da racionalidade que promovem a exclusão de alguns grupos". Assim, a filosofia da educação que direciona/controla a formação de professores e elege as formas de conhecimento $e$ preceitos morais universais para a condução apropriada da prática educativa, tende a legitimar e justificar a ordem existente. De acordo com Jenks (id.ib., ênfase adicional):

Tal como a educação formal, a socialização é um processo violento e doloroso no sentido, muito político, de que todas as pessoas são constrangidas a se tornar determinadas categorias de ser em vez de outras..

Aqui, a teoria social não é meramente descritiva e, portanto, não é "desinteressada". Assim, vemos que a construção social da criança, como outras construções sociais, tem determinadas intenções sociais e politicamente localizadas:

Isto significa que a criança é intencionalmente constituída de forma a apoiar e perpetuar as bases fundamentais $e$ as noções de humanidade, ação, ordem, linguagem $e$ racionalidade de teorias particulares. Somos assim confrontados com diferentes crianças 'teóricas' que servem os diferentes modelos teóricos de vida social do qual emergem (Jenks, 2002:214).

O autor enfatiza ainda que, se a história das ciências sociais tem dado provas de uma crítica sistemática e desmistificadora das ideologias dominantes do capitalismo em relação à classe social, do colonialismo em relação à raça e do patriarcado em relação ao gênero, a ideologia do desenvolvimento tem se mantido, até agora, relativamente intacta no que diz respeito à infância. Para 
realizar essa crítica, o autor retoma o pensamento social do século XIX, no qual o antigo antropólogo "evolucionista" (civilizado $e$ presunçoso) simplesmente "sabia" que o selvagem era "diferente" em termos de evolução e, portanto, merecedor de estudo. Da mesma forma, reconhecemos a criança como diferente e menos desenvolvida que nós (adultos racionais), o que nos autoriza a estudá-la (na verdade, produzi-la com nossas teorias). Ambas as posições, do civilizado em relação ao selvagem e do adulto em relação à criança, derivam de uma teoria ontológica préestabelecida e tácita da diferença, formas não-ditas do conhecimento (porque implícitas) que constituem o ser do "outro"; isto é, sua definição comumente aceita, seja esse outro um "selvagem" ou uma "criança" (id.ib.).

Na perspectiva dos novos estudos sociais sobre a infância, o processo de socialização passa a ser entendido como um processo contínuo, múltiplo em sua direção e fins, tanto os mais imediatamente visíveis quanto os menos perceptíveis, porque comumente não reconhecidos pela visão tradicional de socialização que, além da forma, também limita os agentes do processo de socialização e os territórios em que este tem lugar. Sua análise crítica permite reconhecer uma recomposição referente tanto aos territórios-instituições tradicionais da socialização - como a escola ou a família - quanto dos que atualmente tomam a infância por "alvo", como o mercado e a mídia. ${ }^{8}$

Assim, não se pode mais tomar a socialização apenas em seu sentido clássico (na esteira durkheimiana) e sim numa perspectiva interacionista que considera a socialização um processo contínuo, no qual a criança é levada a construir sua própria experiência em um "quebra-cabeças" de referências e normas. Esse "puzzle" complexifica e multiplica os atores em cena

\footnotetext{
8 Para uma crítica à "utilidade" e também à "perversidade" do conceito de socialização e a proposta de sua releitura pela Sociologia da Infância, ver Ferreira (2000:25-30).
} 
Gênero, infância e relações de poder

na construção da experiência social das crianças contemporâneas (Sirota, 2005).

\section{Invisibilidade social e científica}

A perspectiva dos novos estudos sociais da infância visa ultrapassar os limites da investigação, até agora confinada ao campo médico (pediatria, puericultura), à psicologia do desenvolvimento e à pedagogia - áreas científicas que tradicionalmente se ocuparam das crianças e da infância na primeira modernidade (Sarmento; Pinto, 1997). Essa crítica se estende também à sociologia e à antropologia que, no campo das ciências sociais, igualmente se ocupavam da infância e da criança como "objetos subsumidos" de análise (Marchi, 2007). Isto é, como objetos sempre "deduzidos" das instituições "família" e "escola". O fato de a criança ter sido sempre considerada a partir das instituições que a acolhem fez com que o estatuto de ator social lhe tenha sido comumente negado nas investigações. Embora tomar a criança como "informante" ou "ouvir a voz" da criança já seja considerado "lugar comum" nas pesquisas atuais, as possibilidades e dificuldades de caráter tanto metodológico quanto ético dessa mudança paradigmática - que decorre da crítica ao "adultocentrismo" nas tradicionais técnicas investigativas das ciências sociais - ainda é assunto de intenso debate na área. ${ }^{9}$

A longa ausência da infância e das crianças como objetos de estudo no campo sociológico é dimensionada por Sarmento (2006) como uma "invisibilidade" em 3 tempos: histórica, cívica e científica. Essa invisibilidade pode ser atribuída a causas de duas grandes ordens: uma de "natureza social" e outra de "natureza epistemológica" que, imbricadas, apoiam-se e legitimam-se mutuamente. A causa de ordem social diz respeito à invisibilidade/subalternidade histórica e cívica das crianças

9 Sobre essa questão, ver Delgado e Muller (2005) e Christensen e James (2005). 
relativamente ao mundo dos adultos, à sua concepção de seres incompletos ou "em trânsito" para a idade adulta (o que explicaria sua presença primeira nas ciências médicas, na psicologia e na pedagogia), à sua "privatização" ou confinamento ao espaço doméstico ou instituições sociais de educação e guarda (escolas, creches, orfanatos, etc.). ${ }^{10}$ A causa de ordem epistemológica (invisibilidade científica) diz respeito às críticas às teorias da socialização e às teorias do desenvolvimento infantil presentes na pedagogia e na psicologia do desenvolvimento(adiante brevemente esboçadas).

Os limites - apontados pela sociologia da infância - dos estudos sociais sobre as crianças no contexto norte-americano $e$ europeu, isto é, sua escassez numérica e o estatuto de ator negado às crianças, são válidos também para o caso brasileiro. No Brasil, até a década de 90 , pouquíssimos pesquisadores se voltaram para a infância como objeto de estudo independente. Os estudos de Florestan Fernandes nos anos 40, sobre As trocinhas do Bom Retiro e sobre educação na sociedade Tupinambá (1951), e o de Egon Schaden sobre crianças guaranis são apontados como notáveis exceções (Nunes, 1999, 2002; Cohn, 2005). Mas o levantamento $e$ análise dessa produção na antropologia constatam, além da rarefação, a presença hegemônica das visões culturalista e estrutural-funcionalista, o que impedia que as crianças e suas práticas fossem abordadas em si mesmas. Nessa produção, as crianças eram vistas como receptáculos passivos de papéis funcionais prescritos pela sociedade ou de competências culturais esperadas para a vida adulta. $\mathrm{O}$ estatuto da criança era o do "imaturo", cuja inserção no sistema social/cultural deveria ser fomentada pelos "agentes socializadores", visão presente tanto no

\footnotetext{
${ }^{10}$ A exclusão das crianças da sociedade adulta se dá fundamentalmente em torno dos fatos da vida sexual, da violência, da economia e da política. Essa exclusão, base da "administração simbólica" da infância, elabora um conjunto de normas, interdições e prescrições que condicionam a vida e ação das crianças em sociedade.
} 
Gênero, infância e relações de poder

panorama internacional quanto no nacional no início desta produção (Nunes, 1999, 2002; Castro, 2005; Cohn, 2005).

\section{Gênero e infância como categorias de análise social}

Ao tentar demonstrar as dificuldades e resistências do meio científico à promoção da categoria infância como conceitualmente autônoma, alguns autores da sociologia da infância comparam essas dificuldades à descoberta do gênero como categoria de análise. Pinto (1997), citando A. Touraine e outros sociólogos com o mesmo ponto de vista, afirma que, apesar das especificidades da infância, a reação de alguns setores ao reconhecimento dos direitos da criança tem

paralelos evidentes com o que se passou há 20 anos com as mulheres, há 30 ou 50 anos com os povos colonizados e há cem anos com os trabalhadores, na medida em que todos foram considerados, em determinado momento, deficitários e incapazes (Pinto, 1997:54, ênfase adicional).

As dificuldades tanto de ordem política quanto epistemológica no reconhecimento da denominada "cidadania epistemológica da criança" são similares às resistências com que se depararam, tempos atrás, os "estudos feministas" para estabelecer o gênero como uma nova categoria de análise. Devemos considerar, portanto, que assim como o conceito de gênero demonstrou que não existe "homem" $e$ "mulher" universais, também os atuais estudos sociais da infância demonstram a inexistência de uma infância/criança universal. Essas categorias são construções históricas e sociais não dissociáveis de outras - como classe, etnia e gênero - como demonstram análises comparativas e transculturais (Montandon, 2001; Sirota, 2001). A infância é atravessada, no campo social, pelas relações assimétricas de poder $e$ ação entre adultos $e$ crianças $e$, no campo científico, pela perspectiva adultocêntrica $e$ predominantemente masculina do conhecimento. 
Baseada na antropologia de inspiração feminista, neste artigo sugiro que a proximidade epistêmica da mulher e da criança (o seu silenciamento e sua exclusão) tem origem na sua proximidade física e simbólica no universo social (caracterizada pela posição de subordinação e dependência do mundo adulto masculino). ${ }^{11}$

No campo da literatura feminista, como uma das primeiras reações à hegemonia masculina na vida social, o trabalho de Simone de Beauvoir - O Segundo Sexo (1949) - inaugurou os estudos que passaram a centrar na mulher, especificamente, seu foco de análise. Esses estudos tiveram por característica transformar a mulher em uma categoria analítica separada do homem e, por objetivo, resgatar a presença feminina até então oculta ou esquecida na história oficial que destacava apenas a participação masculina na sua construção.

O termo "gênero" (ou "relações de gênero") surge em seguida na cena científica pela trilha inicial aberta pelos "estudos da mulher", para introduzir (como crítica à ideia essencialista da "mulher universal") o caráter relacional da construção e da apreensão dos sujeitos masculino/feminino nas sociedades. Ou seja, doravante, com o conceito de gênero, entende-se que a compreensão de qualquer uma das partes não pode ser atingida em separado ou isoladamente da outra (Saffioti, 1991). Assim, os "estudos de gênero" vão indicar construções sociais - a criação inteiramente social de ideias sobre os papéis considerados adequados a homens e mulheres, assim como a formação das subjetividades "masculina" e "feminina" que decorrem dessas atribuições sociais (Scott,1990).

Esses movimentos teórico-conceituais possibilitaram, cada qual à sua maneira, uma mudança no próprio âmbito do processo da produção do conhecimento, além da ampliação do conceito de

\footnotetext{
${ }^{11}$ Os estudos de gênero revelaram que a construção social do corpo da mulher (sua constituição física), por si só, inviabilizava sua entrada no mundo dos negócios e da política.
} 
Gênero, infância e relações de poder

cidadania e do direito à história e à memória das mulheres; isto é, a ampliação do campo das experiências históricas consideradas dignas de serem narradas (juntamente com a emergência de novos temas de estudo) (Rago, 1998).

Mas como a antropologia feminista pode nos ajudar a entender que a invisibilidade científica das mulheres atinge, de maneira ainda mais evidente, também as crianças? $\mathrm{O}$ argumento é o de que uma mesma lógica cultural atua no processo de desvalorização (social e epistêmica) destas duas categorias sociais. Sem pretender tornar irrelevantes os fatos biológicos e, portanto, afirmar que homens $e$ mulheres ou crianças $e$ adultos não sejam diferentes, esse argumento ressaltar que certos dados e diferenças somente adquirem significado de superior/inferior na estrutura de sistemas de valores que são cultural $e$ historicamente definidos (Ortner, 1979).

Uma hipótese já bem conhecida na antropologia social é que a posição inferiorizada da mulher na sociedade pode ser explicada, grosso modo, pela oposição de valor entre "natureza" e "cultura" (Ortner, 1979). A mulher estaria, na maioria das sociedades, sendo identificada àquilo que cada cultura considera, não somente distinta, mas inferior a si própria, isto é, a natureza. Ora, uma das evidências demonstrada pelos defensores desse argumento é o fato de que a associação da mulher ao "circulo doméstico" contribui à compreensão de sua proximidade com a "natureza", e que isso acontece por sua constante proximidade ou ligação com as crianças. ${ }^{12} \mathrm{Meu}$ argumento é que as crianças, mais do que qualquer outra categoria social, são culturalmente reconhecidas como pertencendo ao "reino da natureza" $e$, portanto, culturalmente vistas como seres sociais inferiores ou socialmente inacabados e que precisam, através dos processos de

\footnotetext{
${ }^{12}$ Essa ligação tem sido ainda muito comumente associada à maternidade. Para Scavone (2001), apesar das mudanças ocorridas nas sociedades contemporâneas, o "significado social" da maternidade revela que sua realização ainda compromete consideravelmente as mulheres e revela também "uma face importante da lógica da razão androcêntrica”.
} 
socialização e educação, levados a cabo pela família e pela escola (notadamente pelo papel social de "mãe" atribuído à mulher), serem introduzidas à sociedade e cultura a que pertencem.

Assim, percebemos o caráter dual da infância: um fenômeno natural e social ao mesmo tempo. Esse "caráter híbrido" desafia a rígida divisão entre natureza e cultura que, entre outros elementos, está na base da própria divisão entre "ciências naturais" $e$ "ciências sociais". De acordo com Prout (2005), este é o forte motivo pelo qual as ciências sociais negligenciaram, por tanto tempo, a infância como objeto de estudo: ela é um objeto "hibrido", a meio caminho entre a natureza e a cultura.

\section{Vozes infantis: a descolonização epistêmica e social das crianças}

A partir das críticas produzidas pela Sociologia da Infância às teorias tradicionais da socialização expostas neste artigo, vimos que a socialização não pode mais ser vista como uma espécie de "programação cultural" (Pinto, 1997) em que a criança absorve passivamente as influências das realidades com que entra em contato: a criança é também um "ser ativo" nesse processo. Disso se pode concluir, junto com os sociólogos da infância, que as crianças têm consciência dos seus sentimentos, ideias, desejos e expectativas e que são capazes de efetivamente expressá-los. Além disso, como salientam esses sociólogos, existem realidades sociais que somente a partir do ponto de vista das crianças $e$ dos seus universos específicos (as chamadas "culturas infantis") podem ser descobertas, apreendidas e analisadas. É nesse sentido que a etnografia tem sido apontada como metodologia particularmente adequada ao imperativo de "dar voz" às crianças, fazendo-as participar na produção dos dados sociológicos sobre suas maneiras de ser, sentir, agir e pensar. Assim, segundo grande parte dos pesquisadores, os estudos em pequena escala permitem conhecer as ações das crianças como dotadas de sentido com lógica própria. 
Gênero, infância e relações de poder

Além das questões de metodologia e interpretação propriamente voltadas ao mundo das crianças, estudar a infância por "mérito próprio" significa resgatá-la da invisibilidade teórica a que está confinada; significa não deduzi-la simplesmente de instituições como a escola e a familia ou de seus agentes, pais e professores, até agora, os únicos socialmente habilitados - ao lado dos próprios analistas - para falar "sobre" e "em nome" das crianças. O "familialismo" e a "escolarização" das crianças, não é, como lembra Qvortup (1995:06) somente "uma concepção ideológica acerca do lugar que as crianças devem ocupar, mas também um modo metodológico de despojar as crianças do seu direito a serem notadas" e... ouvidas. Segundo o pesquisador, esse fato pode ser melhor percebido nas estatísticas que geralmente utilizam a familia "em nome" de todos os seus membros, subentendendo-se que todos (adultos e crianças) partilham das mesmas condições e interesses. ${ }^{13}$

A autonomia conceitual da infância, proposta pela Sociologia da Infância, não significa, no entanto, estudar o objeto de forma isolada das relações sociais que o constituem: significa, antes, o descentramento do olhar do adulto como condição de percepção das crianças e da inteligibilidade da infância (Sarmento; Pinto, 1997). O recurso às metodologias interpretativas $e$ etnográficas convoca os adultos a desafiarem as barreiras de seu próprio adultocentrismo (Ferreira, 2002).

Assim, particularmente úteis para o estudo da infância, a utilização dos métodos etnográficos não pode deixar de realizar, no entanto, sua articulação com as abordagens de caráter macrosocial, porque a interpretação das "culturas infantis" não pode ser realizada no "vazio social", necessitando estar também apoiada na análise das condições sociais estruturais em que as crianças vivem, interagem $e$ dão sentido ao que fazem. Nesse sentido, os

13 O fato das crianças atualmente passarem grande parte do tempo fora de casa solicita que deva ser reconhecido o uso próprio que faz do seu tempo, em vez de reduzí-lo a apenas mais um elemento da organização do tempo dos pais (Qvortrup, 1995). 
sociólogos da infância defendem a utilização da "teoria da estruturação", de Giddens (notadamente sua noção de "dualidade da estrutura", na qual esta não é apenas o resultado, mas também o meio reflexivo da ação) como tentativa de superação do dualismo teórico - que o interacionismo simbólico tende particularmente a reforçar - entre as instâncias micro/macro ou entre a ação e a estrutura.

Para finalizar, cabe enfatizar que essas reflexões têm por objetivo colocar em perspectiva as tradicionais relações entre gerações que, socialmente estruturadas, acabam também por estruturar identidades e relações sociais muito desiguais de saber e poder entre "adultos" e "crianças". Os estudos de gênero que realizaram com sucesso uma crítica à ciência em relação às desigualdades de sexo, servem de inspiração a essa empreitada. Este artigo tem o sentido, portanto, de problematizar a perspectiva epistêmica adultocêntrica tradicionalmente presente nas pesquisas sobre crianças, sugerindo uma reflexão sobre a perspectiva dominante e seu possível deslocamento nas formas de produção do conhecimento nas ciências sociais e humanas. Mas é importante frisar que se trata aqui da problematização das relações entre gerações na produção científica e não da produção de uma análise que privilegie um sujeito em detrimento do outro, como podem argumentar os refratários ao processo em curso de descolonização da infância e das crianças no campo científico.

\section{Referências bibliográficas}

ALANEN, Leena. Rethinking Socialization, the Family and Childhood. Sociological Studies of Child Development. vol. 3. JAI Press Inc., 1990, pp.13-28.

CASTRO, Lucia R. Under the "economy of protection": the child in the Brazilian society. International Conference - Marginality and Voice: Childwood in Sociology and Society, Alemanha, Bergische Universität Wuppertal, 23-25 June, 2005. 
Gênero, infância e relações de poder

ChARlOT, Bernard. A Ideia de Infância. In: CHARLOT, Bernard. A Mistificação Pedagógica - realidades sociais e processos ideológicos na teoria da educação. Rio de Janeiro, Zahar Ed., 1979, pp.99-149.

Christensen, Pia; JAMES, Allison. (orgs.) Investigação com Crianças Perspectivas e Práticas. Porto, Escola Superior de Educação Paula Frassinetti, 2005.

CoHN, Clarice. Antropologia da Criança. Rio de Janeiro, Jorge Zahar Editor, 2005.

Delgado, Ana Coll; Müller, Fernanda. (orgs.) Educação e Sociedade, vol. 26, nº 91, maio/ago. 2005.

FERREIRA, Manuela. Editorial. Educação, Sociedade \& Culturas. 2002, pp.07-12.

FERREIRA, Manuela. Salvar Corpos, Forjar a Razão - contributos para uma análise crítica da criança e da infância como construção social. Memórias da Educação (7). Lisboa, Instituto de Inovação Educacional, 2000.

JAMES, Allison; JAMES, Adrian L. Constructing Childhood: theory, policy and social pratice. New York, Palgrave Macmillan, 2004.

JAMES, Allison; Prout, Alan. A New Paradigm for the Sociology of Childhood? Provenance, Promise and Problems. In: JAMES, Allison; PROUT, Alan. (orgs.) Constructing and Reconstructing Childhood: Contemporary Issues in the Sociological Study of Childhood. London, The Falmer Press, 1990, pp.7-34.

JENKS, Chris. Constituindo a Criança. Educação, Sociedade \& Culturas, 2002, pp.189-215.

JOBIM E SOUZA, Solange. Re-Significando a Psicologia do Desenvolvimento: uma contribuição crítica à pesquisa da infância. In: KRAMER, Sônia; LeITE, Maria I. (orgs.) Infância: Fios e Desafios da Pesquisa. São Paulo, Papirus, 1996, pp.39-55.

MARCHI, Rita de C. Os sentidos (paradoxais) da infância nas Ciências Sociais: um estudo de sociologia da infância crítica sobre a "nãocriança" no Brasil. Tese de Doutorado em Sociologia, UFSC, 2007. 
MonTANDON, Cléopâtre. Sociologia da Infância: balanço dos trabalhos em língua Inglesa. Cadernos de Pesquisa, n ${ }^{\circ} 112$, São Paulo, mar. 2001, pp.33-59.

NARODOWSKI, Mariano. Infância e Poder: Conformação da Pedagogia Moderna. Bragança Paulista, Ed. da Universidade de S. Francisco, 2001.

NUNES, Ângela. O lugar da criança nos textos sobre sociedades indígenas brasileiras. In: SILVA, Aracy L.; MACEDO, Ana Vera; NunES, Ângela. (orgs.) Crianças Indígenas - Ensaios Antropológicos. São Paulo, Global Editora, 2002, pp.236-277.

- Introdução. In: NUNES, Ângela. A sociedade das crianças A'uwê-Xavante: por uma Antropologia da Criança. Lisboa, Ministério da Educação, 1999, pp.13-71.

ORTNER, Sherry B. Está a mulher para o homem assim como a natureza para a cultura? In: ROSALDO, Michelle Z. e LAMPHERE, Louise. (orgs.) A mulher, a cultura, a sociedade. Rio de Janeiro, Paz e Terra, 1979, pp.95-120.

PINTO, Manuel. A Infância como Construção Social. In: PINTO, Manuel; SARMENTO, Manuel J. (orgs.) As Crianças: Contextos e Identidades. Portugal, Centro de Estudos da Criança, Universidade do Minho, 1997, pp.31-73.

PROUT, Alan. The Future of Childhood. London, Routledge Falmer, 2005.

QVORTRUP, Jens. Childhood in Europe: a New Field of Social Research. In: LYNNE Chisholm et alii. (orgs.) Growing $U p$ in Europe. Contemporary Horizons in Childhood and Youth Studies. New York, Walter de Gruyter, 1995.

RAGO, Margareth. Epistemologia Feminista, Gênero e História. In: PEDRO, Joana; Grossi, Miriam. (orgs.) Masculino, Feminino, Plural. Florianópolis, Ed. Mulheres, 1998.

SAFFIOTI, Heleieth I. B. Contribuições feministas para o estudo da violência de gênero. Cadernos Pagu (16), Campinas-SP, Núcleo de Estudos de Gênero-Pagu/Unicamp, 2001, pp.115-136. 
Gênero, infância e relações de poder

- Novas perspectivas metodológicas de investigação das relações de gênero. In: MORAIS SILVA, M. A. (org.) Mulher em seis tempos. Araraquara, UNESP, 1991.

SARMENTO, Manuel J. Imagens Sociais e (In)Visibilidade da Infância. Relatório da Disciplina. Braga, Universidade do Minho, 2006, pp.85103.

. Sociologia da Infância: correntes e confluências. Cadernos do Noroeste, Série Sociologia, vol. 13, $n^{\circ}$ 2, Braga, IEC/Universidade do Minho, 2000, pp.145-164.

; PINTO, Manuel. As Crianças e a Infância: definindo conceitos, delimitando o campo. In: PINTO, Manuel, SARMENTO, Manuel. As Crianças - Contextos e Identidades. Braga, IEC/Universidade do Minho, 1997, pp.9-30.

SCAVONE, Lucila. A maternidade e o feminismo: diálogo com as ciências sociais. Cadernos Pagu (16), Campinas-SP, Núcleo de Estudos de Gênero-Pagu/Unicamp, 2001, pp.137-150.

SCOTT, Joan. Gênero: uma categoria útil de análise histórica. Educação e Realidade, vol.16, n 2, Porto Alegre, jul/dez. 1990, pp.5-22.

SiROTA, Régine. Petit Objet Insolite ou Champ Constitué? La Sociologie de l'Enfance est-elle encore dans les choux? In: SIROTA, Régine. (org.). Éléments pour une Sociologie de l'Enfance. Rennes, P.U.R., 2006, pp.13-34.

. L'Enfant Acteur ou Sujet dans la Sociologie de l'Enfance évolution des positions théoriques au travers du prisme de la socialisation. In: BERGONNIER-DUPUY, Geneviève. (org.) L'Enfant Acteur et/ou Sujet au Sein de la Famille. Paris, Ed. Erès, 2005, pp.3541.

- Emergência de uma Sociologia da Infância: evolução do objeto e do olhar. Cadernos de Pesquisa, n ${ }^{\circ} 112$, São Paulo, mar. 2001, pp.07-31. 